\title{
Pemetaan Tingkatan Cuaca Ekstrim Masing-Masing Kecamatan di Kota Kupang
}

\author{
Arfita Rahmawati ${ }^{1}$, Bella Theo Tomi Pamungkas ${ }^{2}$, Dwi Partini ${ }^{3}$ \\ ${ }^{1,2}$ Program Studi Pendidikan Geografi Universitas Nusa Cendana \\ ${ }^{3}$ Program Studi Pendidikan Geografi Universitas Pattimura
}

Korespondensi: ararfita@gmail.com

\begin{abstract}
Abstrak
Cuaca ekstrim merupakan salah satu bencana alam yang terjadi di Kota Kupang, Provinsi Nusa Tengga Timur. Seperti bencana alam lainnya, cuaca ektrim juga memberikan dampak kerugian terhadap kehidupan masyarakat. Tujuan penelitian ini untuk mengetahui luasan tingkatan cuaca ekstrim pada masing kecamatan yang terdapat di Kota Kupang dengan pemetaan. Penelitian ini termasuk dalam penelitain deskriptif kuantitatif, kemudian populasi sekaligus sampel yang digunakan adalah Kota Kupang. Metode pengumpulan data digunakan pengamatan. Selanjutnya teknik analisis data digunakan analisis overlay dengan metode skoring dengan parameter curah hujan, tutupan lahan, dan kelas lereng. Kemudian dilakukan pembagian tiga kelas tingkatan cuaca ekstrim yaitu rendah, sedang, dan tinggi. Berdasarkan hasil penelitian sebesar $79,53 \%$ atau dengan luas $143,399 \mathrm{~km}^{2}$ Kota Kupang termasuk dalam wilayah cuaca ektstrim dengan kriteria tinggi. Kecamatan yang memiliki persentase luasan paling besar terhadap cuaca ekstrim tingkat tinggi di Kota Kupang adalah kecamatan Kota Lama. Sedangkan kecamatan yang memiliki persentase luasan paling besar terhadap cuaca ekstrim dengan tingkat rendah adalah kecamatan Alak.
\end{abstract}

Kata Kunci: pemetaan, cuaca ekstrim, kecamatan di Kota Kupang

\begin{abstract}
Extreme weather is one of the natural disasters that occur in Kupang City, East Nusa Tengga Province. Like other natural disasters, extreme weather also has a detrimental impact on people's lives. The purpose of this study was to determine extreme weather levels in each sub-district in Kupang City with mapping. The research used quantitative descriptive research, then the population as well as the sample used is Kupang City. The data collection method used observation. The data analysis technique used overlay analysis with the scoring method with parameters of rainfall, land use, and slope. Then divided into three classes of extreme weather levels, low, medium, and high. Based on the research results, it is $79.53 \%$ or with an area of $143.399 \mathrm{~km} 2$, Kupang is included in the extreme weather area with high criteria. The sub-district that has the largest percentage area of high-level extreme weather in Kota Kupang is the Kota Lama sub-district. Meanwhile, the sub-district that has the largest percentage of area to extreme weather with a low level is Alak sub-district.
\end{abstract}

Key words: mapping, extreme weather, sub-district in Kupang City 


\section{Pendahuluan}

Tren pemanasan global yang semakin meningkat, bencana alam yang sering terjadi membawa tantangan yang serius bagi pembangunan masyarakat yang berkelanjutan (Zhou, et al., 2018: 568). Dalam beberapa tahun terakhir, peristiwa bencana alam sangat sering terjadi baik yang disebabkan oleh peristiwa geologi seperti gempa bumi, gunung meletus, dan tsunami, maupun kejadian bencana yang disebabkan oleh klimatologi dan hidrometerologi (Fahrimal, Reza, and Tjoetra, 2019: 128). Berdasarkan data World risk report 2018, Indonesia menduduki urutan ke-36 dengan indeks risiko 10,36 dari 172 negara paling rawan bencana alam di dunia (Hadi, 2019: 30).

Salah satu dari bencana yang terjadi di Indonesia adalah cuaca ekstrim. Cuaca ekstrim yang terjadi dapat menyebabkan bencana hidrometeorologi. Cuaca ekstrim adalah informasi cuaca dan iklim yang semakin meningkat seiring dengan meningkatnya fenomena alam yang tidak lazim terjadi atau biasa (Caraka, et al., 2015: 105). Dampak kondisi penyimpangan iklim (cuaca ekstrim) yang nyatanya adalah meningkatnya intensitas curah hujan, banjir bandang dan banjir pasang, badai lokal, suhu perkotaan naik, kekeringan dan tanah longsor.(Mananohas, et al., 2019: 169). Kerugian akibat cuaca ekstrim dapat mencakup kedua jenis; kerugian moneter (kerusakan bangunan dan properti lain yang dapat diperbaiki atau diganti), serta dampak non-moneter seperti hilangnya nyawa, dampak kesehatan, dan kerusakan yang tidak dapat dipulihkan seperti erosi pantai, dampak ekosistem dan dampak sosial (Calliari, et al., 2019: 16). Dalam kasus di Nusa Tenggara Timur itu sendiri cuaca ekstrim ini sering berafiliasi dengan eksistensi siklon (badai) tropis dan efek anomaly iklim, baik El Nino atau La Nina (Norman, 2014: 16).

Pengkajian cuaca ekstrem di Provinsi Nusa Tenggara Timur menggunakan teknik analisis overlay dengan skoring berdasarkan dari Perka No. 2 BNPB Tahun 2012 sehingga diketahui tingkatan cuaca ekstrim di masing-masing kecamatan yang sudah dipetakan. Berdasarkan Peraturan KBMKG Nomor : KEP.009 tahun 2010 dan Perka No. 2 BNPB Tahun 2012 diketahui aspek penskoran cuaca ekstrim dari aspek intensitas curah hujan, penggunaan lahan, dan kelas lereng (Badan Meteorologi Klimatologi dan Geofisika, 2010:2). Penggunaan landsat 8 OLI memainkan elemen kunci penting dalam memantau penggunaan lahan dalam pemetaan (Ridwan, et al., 2018: 438). Citra landsat 8 memiliki resolusi 30 meter dengan sebelas pita spektral dengan resolusi spasial 30 meter untuk pita 1-7 dan 9, 15 meter untuk pita 8, dan 100 meter untuk pita 10 dan 11 sehingga dapat 
digunakan untuk pemantauan penggunaan lahan (Vera, et al., 2021: 2). Data DEM Kota Kupang digunakan untuk membuat peta kelas lereng dengan pembagian brdasarkan klasifikasi van zuidam. Dengan menggunakan hasil dari peta curah hujan, peta penggunaan lahan dan peta kelas lereng dapat dibuat peta tingkatan cuaca ekstrim sehingga dapat diketahui persentase luasan tingkat cuaca ekstrim yang terjadi pada masing-masing kecamatan di Kota Kupang.

\section{Metode}

Penelitian ini merupakan penelitian deskriptif kuantitatif. Populasi menggunakan keruangan, dalam penelitian ini populasinya adalah Kota Kupang. Sampel yang digunakan adalah sampel jenuh. Sampel jenuh adalah teknik penentuan sampel apabila semua anggota populasi digunakan sebagai sampel (Sugiyono dalam Darmayanti, 2019: 2312). Metode pengumpulan data dengan pengamatan. Teknik analisis data mengunakan analisis overlay dengan metode skoring terhadap parameter-parameter penyusun, seperti: curah hujan, penggunaan lahan, dan kelas lereng. Untuk parameter curah hujan digunakan analisis polygon thiessen dengan menggunakan data dari 3 stasiun pencatat hujan dari tahun 2015-2020 yaitu: sta el-tari, sta Kupang, dan sta Lasiana. Kemudian dihitung rata-rata terbobot, masing-masing stasiun hujan ditentukan luas daerah pengaruhnya berdasarkan poligon yang dibentuk (menggambarkan garis-garis sumbu pada garis-garis penghubung antara dua stasiun hujan yang berdekatan) (Ningsih, 2012:156). Parameter penggunaan lahan menggunakan data dari landsat 8 Oli kemudian dilakukan analisis klasifikasi terbimbing. Klasifikasi terbimbing adalah klasifikasi yang dilakukan dengan arahan analis (supervised), dimana kriteria pengelompokkan kelas ditetapkan berdasarkan penciri kelas yang diperoleh melalui pembuatan area contoh (Purwanto and Lukiawan, 2019:68). Selanjutnya parameter kelas lereng didapatkan dari analisis data Dem Kota Kupang dengan menggunakan raster analisis (slope) yang kemudian masukan ke dalam klasifikasi van zuidam. Selanjutnya dari parameter curah hujan, penggunaan lahan, dan kelas lereng dibuat peta tingkatan cuaca ekstrim mengunakan analisis overlay dengan metode skoring dengan 3 kelas tingkatan, yaitu rendah, sedang, dan tinggi. 


\section{Pembahasan}

Berbagai penelitian terkait mengenai cuaca ekstrim yang telah dilakukan, ada yang melihat dari parameter curah hujan saja seperti dalam penelitian oleh Mirawati (2013: 239) dengan judul "Prediksi Curah Hujan dengan Metode Kalman Filter (Studi Kasus di Kota Semarang Tahun 2012)". Selain itu adapula penelitian oleh Kurniawan (2018:1) menggunakan parameter curah hujan, suhu permukaan air laut, dan pengamatan udara atas dengan judul "Analisis Cuaca Ekstrem Terkait Bencana Hidrometeorologi di Jayapura (Studi Kasus Hujan Lebat Tanggal 22 Februari 2014)". Dalam penelitian ini menggunakan parameter curah hujan dari penelitian Mirwati dan Kurniawan dengan ditambah parameter penggunaan lahan dan kelas lereng. Parameter curah hujan, penggunaan lahan, dan kelas lereng digunakan untuk mengetahui pembagian tingkatan cuaca ekstrim pada masing-masing kecamatan di Kota Kupang.

\section{Curah Hujan Kota Kupang}

Data curah hujan menggunakan data tahun 2015 - 2020. Untuk analisis menggunakan analisis polygon thiessen dengan memasukan data intensitas curah hujan masing-masing stasiun curah hujan. Hasil dari analisis polygon thiessen selanjutnya dipetakan, hasilnya sebagai berikut :

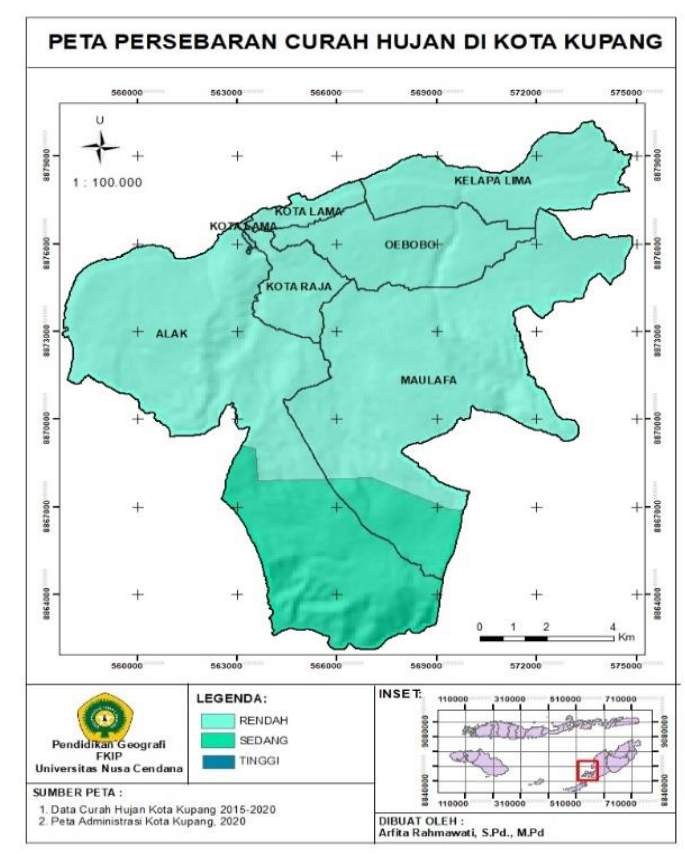

Gambar 1. Peta Sebaran Curah Hujan di Kota Kupang

Dari hasil analisis polygon thiessen tersebut diitung luasnya dan hasilnya sebagai berikut: 
Tabel 1. Persentase Berdasarkan Intensitas Curah Hujan

\begin{tabular}{clcc} 
No & Intensitas Curah Hujan & Luas $\left.\mathbf{( K m}^{2}\right)$ & Persentase $(\%)$ \\
\hline 1 & Rendah $(<60 \mathrm{~mm})$ & 139,53417 & 77,39 \\
2 & Sedang $(60-100 \mathrm{~mm})$ & 40,76583 & 22,61 \\
3 & Tinggi $(>100 \mathrm{~mm})$ & 0 & 0 \\
\hline
\end{tabular}

Sumber: Hasil Penelitian, 2020

Berdasarkan tabel 1 diketahui intensitas curah hujan dari tahun 2015-2020 di Kota Kupang paling banyak berada dalam intensitas rendah, dengan nilai kurang dari $60 \mathrm{~mm}$ persentase luasan $77,39 \%$ atau sebesar $139,53417 \mathrm{~km}^{2}$. Sedangkan intensitas curah hujan kategori sedang di Kota Kupang memiliki persentase luasan $22,61 \%$ atau sebesar $40,76583 \mathrm{~km}^{2}$.

\section{Penggunaan Lahan Kota Kupang}

Penggunaan Lahan di Kota Kupang didapatkan dari data Landsat 8 Tahun 2020, dengan menggunakan klasifikasi terbimbing dengan 4 kelas, selanjutkan dilakukan pemetaan dengan hasil sebagai berikut:

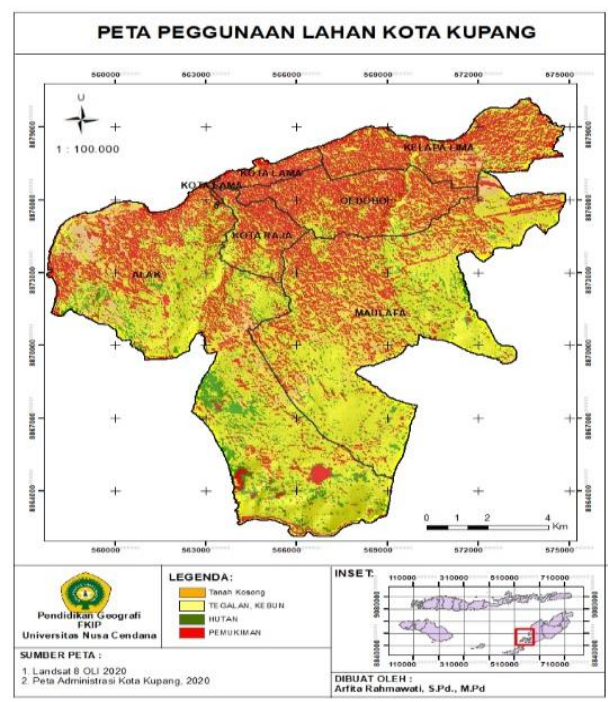

Gambar 2. Peta Penggunaan Lahan Kota Kupang

Dari hasil klasifikasi terbimbing selanjutnya dihitung luasan masing-masing penggunaan lahan. Hasilnya sebagai berikut:

Tabel 2. Persentase Luasan Penggunaan Lahan

\begin{tabular}{clcc} 
No & Penggunaan Lahan & Luas $\left(\mathbf{K m}^{2}\right)$ & Persentase (\%) \\
\hline 1 & Tanah Kosong & 7,26609 & 4,03 \\
2 & Tegalan & 79,74669 & 44,23 \\
3 & Hutan & 17,34486 & 9,62 \\
4 & Pemukiman & 75,94236 & 42,12 \\
\hline
\end{tabular}

Sumber: Hasil Penelitian, 2020 
Jurnal geoedusains, Volume 2, Nomor 1, Juni 2021

Berdasarkan tabel 2 penggunaan lahan paling tinggi adalah tegalan dengan persentase $44,23 \%$ dan yang paling rendah adalah tanah kosong dengan persentase $4,03 \%$.

Klasifikasi Kelas Lereng

Klasifikasi kelas lereng didapatkan dari data DEM Kota Kupang, pembagian kelas lereng berdasarkan klasifikasi Van Zuidam. Pengklasifikasian sebagai berikut:

Tabel 3. Persentase Kemiringan Lereng Van Zuidam

\begin{tabular}{cccc} 
No & & Kelas & Persentase (\%) \\
\hline 1 & Kelas 1 & $0-2$ \\
2 & Kelas 2 & $3-7$ \\
3 & Kelas 3 & $8-13$ \\
4 & Kelas 4 & $14-20$ \\
\hline
\end{tabular}

Sumber: Van Zuidam dalam Listyani R.A., 2019: 333

Berdasarkan pengklasifikasian kelas tersebut selanjutnya dilakukan pemetaan dengan hasil :

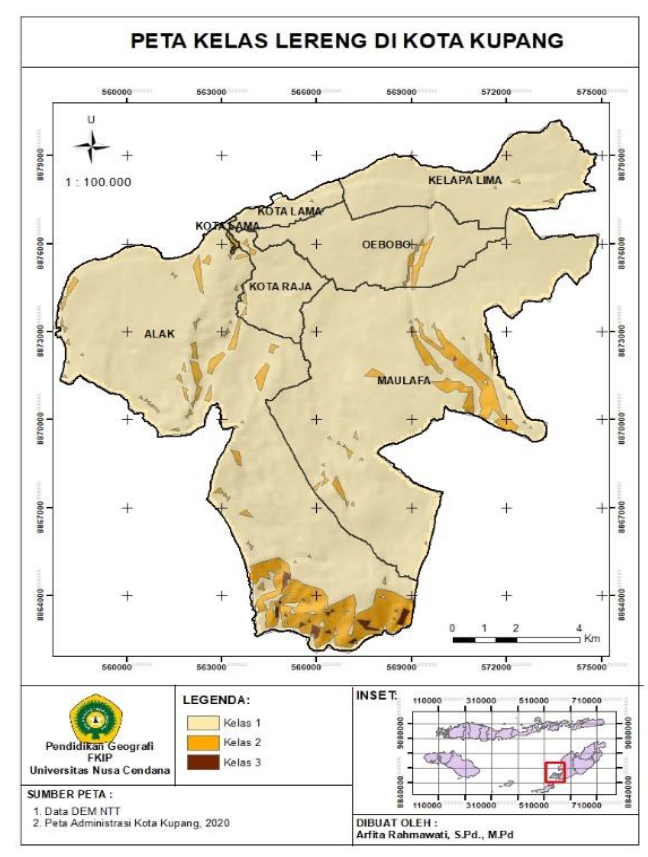

Gambar 3. Peta Kelas Lereng di kota Kupang

Dari peta yang dihasilkan kemudian dilakukan pengukuran luas masing-masing kelas lereng, hasilnya sebagai berikut:

Tabel 4. Persentase Luasan Kelas Lereng

\begin{tabular}{|c|c|c|c|}
\hline No & Kelas Lereng & Luas $\left(\mathrm{Km}^{2}\right)$ & Persentase (\%) \\
\hline 1 & Kelas 1 & 139,40796 & 77,32 \\
\hline 2 & Kelas 2 & 34,65366 & 19,22 \\
\hline 3 & Kelas 3 & 6,23838 & 3,46 \\
\hline 4 & Kelas 4 & 0 & 0 \\
\hline
\end{tabular}

Sumber: Hasil Penelitian, 2020 
Berdasarkan tabel 4 diketahui wilayah Kota Kupang termasuk dalam lereng kelas 1 (landai) dengan persentase $77,32 \%$ atau luas $139,40796 \mathrm{~km}^{2}$.

\section{Pemetaan Cuaca Ekstrim di Kota Kupang}

Untuk membuat peta cuaca ekstrm berpedoman pada Peraturan KBMKG Nomor : KEP.009 tahun 2010. Sebelum dilakukan analisis overlay, terlebih dulu dilakukan skoring terhadap aspek intensitas curah hujan, penggunaan lahan, dan kelas lereng sebagai berikut:

Tabel 5. Skoring Masing-Masing Aspek

\begin{tabular}{clc} 
Aspek & \multicolumn{1}{c}{ Kriteria } & Skor \\
\hline Intensitas Curah Hujan & Rendah & 3 \\
& Sedang & 2 \\
& Tinggi & 1 \\
Penggunaan Lahan & Sawah, Tegalan, Tanah Kosong & 3 \\
& Pemukiman & 2 \\
& Hutan & 1 \\
Kelas Lereng & Kelas 1 dan Kelas 2 & 3 \\
& Kelas 3 & 2 \\
\hline
\end{tabular}

Sumber: Peraturan KBMKG Nomor : KEP.009 tahun 2010

Dari tabel 5, dibuat perentangan nilai dengan skala likert untuk mendapatkan nilai total setelah dilakukan overlay.

Tabel 6. Tingkatan Cuaca Ekstrim

Cuaca Ekstrim Rendah

Cuaca Ekstrim Sedang

Cuaca Ekstrim Tinggi

Sumber: Peraturan KBMKG Nomor : KEP.009 tahun 2010

Kemudian dipetakan dan hasil pemetaannya sebagai berikut:

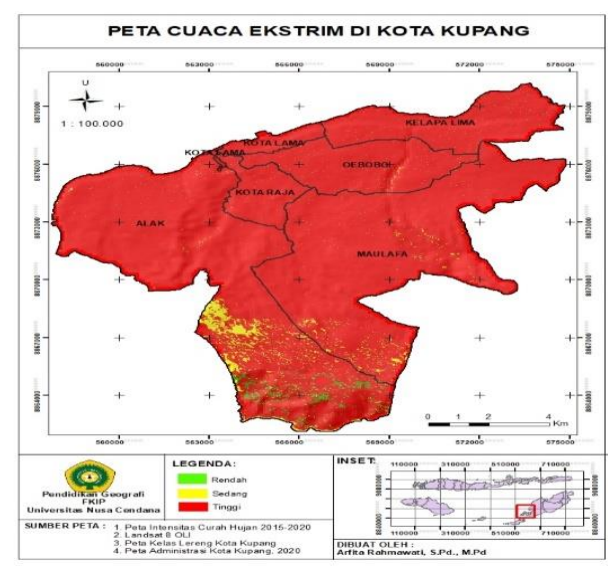

Gambar 4. Peta Persebaran Cuaca Ekstrim di Kota Kupang

Pemetaan Tingkat Cuaca Ekstrim ...

Arfita Rahmawati, Bella Theo Tomi Pamungkas, Dwi Partini 
Jurnal geoedusains, Volume 2, Nomor 1, Juni 2021

Berdasarkan gambar 4 selanjutnya dilakukan perhitungan luas persebaran cuaca ekstrim di Kota Kupang berdasarkan kriteria tingkatan sebagai berikut

Tabel 7. Kriteria Tingkatan Cuaca Ekstrim di Kota Kupang

\begin{tabular}{|c|c|c|}
\hline Kriteria & Luas $\left(\mathrm{km}^{2}\right)$ & Persentase (\%) \\
\hline Rendah & 10,316 & 5,72 \\
\hline Sedang & 26,555 & 14,73 \\
\hline Tinggi & 143,399 & 79,53 \\
\hline
\end{tabular}

Sumber: Hasil Penelitian, 2020.

Setelah diketahui luasan pembagian kriteria tingkatan cuaca ekstrim di Kota Kupang, dilakukan penghitungan luasan pada masing-masing kecamatan. Hasilnya dapat dilihat pada tabel 8 sebagai berikut:

Tabel 8. Kriteria Tingkatan Cuaca Ektstrim pada Masing-Masing Kecamatan

\begin{tabular}{cccc} 
Kecamatan & Kriteria Tingkatan & Luas $\left.\mathbf{( k m}^{\mathbf{2}}\right)$ & Persentase $(\%)$ \\
\hline Alak & Rendah & 10,316217 & 11,87 \\
& Sedang & 18,650886 & 21,46 \\
& Tinggi & 57,942897 & 66,67 \\
\hline Kelapa Lima & Rendah & 0 & 0 \\
& Sedang & 1,009344 & 6,72 \\
& Tinggi & 14,010656 & 93,28 \\
\hline Kota Raja & Rendah & 0 & 0 \\
& Sedang & 0,43371 & 7,11 \\
& Tinggi & 5,66629 & 92,89 \\
\hline Kota Lama & Rendah & 0 & 0 \\
& Sedang & 0,210588 & 6,54 \\
& Tinggi & 3,009412 & 93,46 \\
\hline Maulafa & Rendah & 0 & 0 \\
& Sedang & 5,10736 & 9,32 \\
& Tinggi & 49,69264 & 90,68 \\
\hline Oebobo & Rendah & 0 & 0 \\
& Sedang & 1,143288 & 8,04 \\
& Tinggi & 13,076712 & 91,96
\end{tabular}

Sumber: Hasil penelitian, 2020

Berdasarkan tabel 8 diketahui berdasarkan luasan wilayah yang berdasarkan kriteria tingkatan cuaca ekstrim rendah, sedang dan tinggi sebagai berikut:

1. Kecamatan Alak sebesar $11,87 \%$ termasuk tingkatan rendah, $21,465 \%$ sedang, dan $66,67 \%$ tinggi.

2. Kecamatan Kelapa Lima sebesar $0 \%$ termasuk tingkatan rendah, 6,72\% sedang, dan $93,28 \%$ tinggi.

3. Kecamatan Kota Raja sebesar 0\% termasuk tingkatan rendah, 7,11\% sedang, dan $92,89 \%$ tinggi. 
4. Kecamatan Kota Lama sebesar $0 \%$ termasuk tingkatan rendah, 6,54\% sedang, dan $93,46 \%$ tinggi.

5. Kecamatan Maulafa sebesar 0\% termasuk tingkatan rendah, 9,32\% sedang, dan $90,68 \%$ tinggi.

6. Kecamatan Oebobo sebesar 0\% termasuk tingkatan rendah, 8,04\% sedang, dan $91,96 \%$ tinggi.

Kemudian kecamatan yang memiliki persentase luasan paling besar terhadap cuaca ekstrim yang tinggi di Kota Kupang adalah kecamatan Kota lama dengan luas 3,009412 $\mathrm{km}^{2}$ atau dengan persentase 93,46\%. Kemudian persentase luasan paling besar terhadap cuaca ekstrim yang rendah adalah kecamatan Alak dengan luas $10,316217 \mathrm{~km}^{2}$ atau dengan persentase $11,87 \%$.

\section{Kesimpulan}

Berdasarkan hasil penelitian ini dapat disimpulkan:

1. Sebesar $79,53 \%$ atau dengan luas $143,399 \mathrm{~km}^{2}$ Kota Kupang termasuk dalam wilayah cuaca ektstrim dengan kriteria tinggi.

2. Kecamatan yang memiliki persentase luasan paling besar terhadap cuaca ekstrim tingkat tinggi di Kota Kupang adalah kecamatan Kota lama.

3. Kecamatan yang memiliki persentase luasan paling besar terhadap cuaca ekstrim tingkat rendah adalah kecamatan Alak.

\section{Daftar Pustaka}

Badan Meteorologi Klimatologi dan Geofisika. 2010. "Prosedur Standar Operasi Pelaksanaan Peringatan Dini Pelaporan Dan Diseminasi Informasi Cuaca Ekstrim." : $1-16$.

Calliari, Elisa, Swenja Surminski, and Jaroslav Mysiak. 2019. The Politics of (and Behind) the UNFCCC's Loss and Damage Mechanism. Springer: Switzerland.

Caraka, Rezzy Eko, Hasbi Yasin, and Suparti. 2015. "Pemodelan Tinggi Pasang Air Laut Di Kota Semarang Dengan Menggunakan Maximal Overlap Discrete Wavelet Transform (MODWT)." Jurnal Meteorologi Klimatologi Dan Geofisika 2(2): 104-14.

Darmayanti, I Gusti Ayu Diah Novita Yanti dan Ni Putu Ayu. 2019. "Pengaruh Profitabilitas, Ukuran Perusahaan, Struktur Modal, Dan Likuiditas Terhadap Nilai Perusahaan Makanan Dan Minuman." Jurnal Managemen 8(4): 2297-2324.

Fahrimal, Yuhdi, Muhammad Reza, and Afrizal Tjoetra. 2019. "Revolusi Industri 4.0 Dalam Penguatan Kesiapsiagaan Bencana Di Indonesia." Communication 10(2): 128.

Hadi, Hasrul. 2019. "Penguatan Kesiapsiagaan Stakeholder Dalam Pengurangan Resiko Bencana Gempabumi." Geodika 3(1): 30-40.

Kurniawan, Pande Made Rony. 2018. "Analisis Cuaca Ekstrem Terkait Bencana 
Hidrometeorologi Di Jayapura (Studi Kasus Hujan Lebat Tanggal 22 Februari 2014)." Jurnal Meteorologi Klimatologi dan Geofisika 5(3): 1-13.

Listyani R.A., T. 2019. "Criticise of Van Zuidam Classification: A Purpose of Landform Unit." 2019(November): 332-37.

Mananohas, Maharani, Maria D. Bobanto, and Ferdy. 2019. "Hubungan Cuaca Dan Tanaman Pangan Menggunakan Regresi Linear Di Kota Tondano." Jurnal $\begin{array}{llll}\text { Matematika dan } & \text { 8plikasi }\end{array}$ https://ejournal.unsrat.ac.id/index.php/decartesian.

Mirawati, Tika Dhiyani, Hasbi Yasin, and Agus Rusgiyono. 2013. "Prediksi Curah Hujan Dengan Metode Kalman Filter (Studi Kasus Di Kota Semarang Tahun 2012)." JURNAL GAUSSIAN 2(2012): 239-48.

Ningsih, Dewi Handayani Untari. 2012. "Metode Thiessen Polygon Untuk Ramalan Sebaran Curah Hujan Periode Tertentu Pada Wilayah Yang Tidak Memiliki Data Curah Hujan." Jurnal Teknologi Informasi DINAMIK Volume 17(No 2): 154-63.

Norman, P.L.B, and M.Sc Riwu Kaho, SP. 2014. Panduan Interpretasi Dan Respon Informasi Iklim Dan Cuaca Untuk Petani Dan Nelayan. Kupang, Nusa Tenggara Timur: Perkumpulan Pikul-Kupang.

Purwanto, Endi Hari, and Reza Lukiawan. 2019. "Parameter Teknis Dalam Usulan Standar Pengolahan Penginderaan Jauh: Metode Klasifikasi Terbimbing." Jurnal Standardisasi 21(1): 67-78.

Ridwan, M. A. et al. 2018. "Applications of Landsat-8 Data: A Survey." International Journal of Engineering and Technology(UAE) 7(4): 436-41.

Vera L.S. Arrudaa, b, Valderli J. Piontekowskia, Ane Alencara, Reginaldo S. Pereirab, Eraldo A. T. Matricardi. 2021. "An Alternative Approach for Mapping Burn Scars Using Landsat Imagery, Google Earth Engine, and Deep Learning in the Brazilian Savanna | Enhanced Reader." Remote Sensing Application Society and Environtment 22(100472): 1-11.

Zhou, Lei, Xianhua Wu, Zeshui Xu, and Hamido Fujita. 2018. "Emergency Decision Making for Natural Disasters: An Overview." International Journal of Disaster Risk Reduction 27: 567-76. 